\title{
Reclassification of Brevibacillus brevis strains NCIMB 13288 and DSM 6472 (=NRRL NRS-887) as Aneurinibacillus danicus sp. nov. and Brevibacillus limnophilus sp. nov.
}

\author{
Keiichi Goto, ${ }^{1}$ Rieko Fujita, ${ }^{1}$ Yuko Kato, ${ }^{1}$ Mika Asahara ${ }^{1}$ \\ and Akira Yokota ${ }^{2}$ \\ ${ }^{1}$ Microbiological and Analytical Group, Food Research Laboratories, Mitsui Norin Co. Ltd, \\ 223-1, Miyahara, Fujieda, Shizuoka 426-0133, Japan \\ ${ }^{2}$ Institute of Molecular and Cellular Biosciences, University of Tokyo, 1-1, Yayoi 1-chome, \\ Bunkyo-ku, Tokyo 113-0032, Japan
}

Correspondence

Keiichi Goto

kgoto@mnk.co.jp

\begin{abstract}
Comparison of the hypervariable region (269-279 bases in length) at the $5^{\prime}$ end of the 16S rDNA sequences of 29 bacterial strains that were identified previously as Brevibacillus brevis showed that 13 strains clustered with Aneurinibacillus species, eight strains clustered with Bacillus species and eight strains clustered with Brevibacillus species. Based on DNA-DNA hybridization results, 27 strains, not including [Brevibacillus brevis] NCIMB 13288 and [Brevibacillus brevis] DSM 6472, were reidentified as Aneurinibacillus migulanus, Aneurinibacillus thermoaerophilus, Bacillus methanolicus, Bacillus oleronius, Brevibacillus agri, Brevibacillus brevis and Brevibacillus parabrevis. [Brevibacillus brevis] NCIMB 13288, which was located in the Aneurinibacillus cluster, showed low DNA-DNA relatedness ( $<14 \%)$ and low $16 \mathrm{~S}$ rDNA sequence similarity (96-8-97.9\%) to other Aneurinibacillus species. [Brevibacillus brevis] DSM 6472, which was located in the Brevibacillus cluster, also showed low DNA-DNA relatedness $(<12 \%)$ and low 16S rDNA sequence similarity (95.4-98.8\%) to other Brevibacillus species. These genotypic and phylogenetic data, plus phenotypic and chemotaxonomic characteristics, suggest that [Brevibacillus brevis] NCIMB 13288 (=IAM 15048) and [Brevibacillus brevis] DSM 6472 (=NRRL NRS-887) represent novel species of the genera Aneurinibacillus and Brevibacillus, respectively, for which the names Aneurinibacillus danicus sp. nov. and Brevibacillus limnophilus sp. nov. are proposed.
\end{abstract}

Bacillus brevis was first described by Migula (1900). Subsequently, many strains, including some that were not in accordance with the criteria of Bacillus brevis sensu stricto, were classified as Bacillus brevis, according mainly to phenotype; as a result, Bacillus brevis has become a heterogeneous species, similar to Bacillus circulans (Nakamura \& Swezey,

Published online ahead of print on 12 September 2003 as DOI 10.1099/ijs.0.02906-0.

Abbreviation: $\mathrm{HV}$, hypervariable.

The GenBank/EMBL/DDBJ accession numbers for the 16S rDNA sequences obtained in this study are AB112712-AB112731, as detailed in Fig. 2.

Tables showing differential characteristics between strain NCIMB $13288^{\top}$ and related Aneurinibacillus strains and between strain DSM $6472^{\top}$ and related Brevibacillus strains, and a figure showing consensus nucleotide sequences, are available as supplementary material in IJSEM Online.
$1983 a, b)$. In the 1990s, based on polyphasic taxonomic studies of Bacillus brevis and its relatives, many species or strains were reclassified as novel species of the genera Brevibacillus and Aneurinibacillus (Nakamura, 1991, 1993; Takagi et al., 1993; Shida et al., 1994a, b, 1995, 1996; MeierStauffer et al., 1996; Heyndrickx et al., 1997). Recently, Brevibacillus invocatus was proposed as a novel species, according to the polyphasic identification of Bacillus and Brevibacillus strains from clinical, dairy and industrial specimens (Logan et al., 2002). Thus, at the time of writing, 11 species are recognized to belong to the genus Brevibacillus and three species are recognized to belong to the genus Aneurinibacillus. However, with the exception of the thermophilic species Brevibacillus thermoruber and Aneurinibacillus thermoaerophilus, distinguishing between these species is extremely difficult, as most strains are unreactive or weak in many biochemical tests and few have useful differential phenotypic characteristics (Heyndrickx 
et al., 1997; Logan et al., 2002). Even with molecular analyses, such as amplified rDNA restriction analysis (ARDRA), identification of these species is not always simple (Logan et al., 2002). In our previous studies, we demonstrated that a hypervariable (HV) region that corresponds to the $5^{\prime}$ end of $16 \mathrm{~S}$ rDNA (nucleotide positions 70-344; Bacillus subtilis numbering) is a useful marker for rapid identification and grouping of Alicyclobacillus species (Goto et al., 2002a, b), Bacillus species (Goto et al., 2000) and Paenibacillus species (Goto et al., 2002c). In this study, to ascertain how well the region is conserved within Brevibacillus species, we investigated sequence similarities among 29 strains that were supplied as Brevibacillus brevis.

Fifty-two strains were obtained from DSMZ (Deutsche Sammlung von Mikroorganismen und Zellkulturen $\mathrm{GmbH}$, Braunschweig, Germany), IAM (Institute of Molecular and Cellular Biosciences, University of Tokyo, Tokyo, Japan), NBRC/IFO (NITE Biological Resource Center/ Institute for Fermentation, Osaka, Japan) and NCIMB (National Collection of Industrial and Marine Bacteria, Aberdeen, UK). All strains were grown in nutrient broth and agar, or brain heart infusion broth and agar (Difco), at the optimum growth temperature $\left(35\right.$ or $\left.50{ }^{\circ} \mathrm{C}\right)$.

During phenotypic characterization of organisms, unless indicated otherwise, the methods described by Gordon et al. (1973) were used. Acidification was examined with API 50 $\mathrm{CH}$ test strips (bioMérieux) at the optimum growth temperature. Hydrolysis of DNA was determined by using DNase test agar (Difco). Oxidase activity was determined by using the bioMerieux oxidase test. Each test was repeated three times.

For quinone analysis, cells were grown in $100 \mathrm{ml}$ nutrient broth at the optimum growth temperature in a reciprocal shaker for $24 \mathrm{~h}$. Quinones were extracted from freeze-dried cells according to Sano et al. (1996) and analysed by using an Alliance HPLC system that was equipped with a Waters 996 Photodiode Array detector. A Mightysil RP-18 column $(4 \cdot 6 \times 250 \mathrm{~mm}$; Kanto Chemical) was used for separation and methanol/propan-2-ol $(3: 1, \mathrm{v} / \mathrm{v})$ was used as the eluent. Quinones were identified by their UV spectra. For fatty acid analysis, cells were grown on trypticase soy agar (Difco) at the optimum growth temperature for $24 \mathrm{~h}$, as recommended by the manufacturers of the Microbial Identification system (MIS; Microbial ID). Fatty acid methyl esters were extracted from fresh wet biomass by saponification and methylation, according to Bligh \& Dyer (1959) and Metcalfe et al. (1996), and analysed by using MIS software (version 4.02).

Genomic DNA was extracted and purified by using a High Pure PCR Template Preparation kit (Roche). For DNADNA hybridization, genomic DNA was extracted by using a Qiagen Blood and Cell Culture DNA Maxi kit and purified by equilibrium centrifugation in $\mathrm{CsCl} /$ ethidium bromide gradients (Treisman, 1989) by using an OptimaTM MAX Ultracentrifuge (Beckman Coulter). Samples were desalted by using an Ultrafree-4 Centrifugal Filter unit (Millipore). Genetic relatedness was determined fluorometrically with photobiotin-labelled DNA probes and microplates, as described by Ezaki et al. (1989), by using a CytoFluor Series 4000 multiwell plate reader (PerSeptive Biosystems). Hybridization was carried out under stringent conditions (optimal renaturation temperature $+15^{\circ} \mathrm{C}$ ) for $3 \mathrm{~h}$. Renaturation temperatures were based on the DNA G $+\mathrm{C}$ contents of the type strains of Aneurinibacillus aneurinilyticus $(43 \cdot 3 \%)$, Bacillus methanolicus (38.6\%), Bacillus oleronius $(34.9 \%)$ and Brevibacillus brevis $(47 \cdot 3 \%)$ (Ezaki et al., 1989). Each hybridization experiment was repeated at least three times. DNA G $+\mathrm{C}$ contents were determined by HPLC using purified genomic DNA solution, as described previously (Tamaoka \& Komagata, 1984), with genomic DNA of Bacillus subtilis IAM $12118^{\mathrm{T}}$ as a control.

Almost-complete sequences were determined by using a $16 \mathrm{~S}$ rRNA Gene kit (Applied Biosystems). Universal primers for amplification and sequencing of the HV region were: forward primer (F-1), 5'-GCYTAAYACATGCAAGTCGARCG-3' (corresponding to nucleotides 47-69 of Bacillus subtilis $16 \mathrm{~S} \mathrm{rDNA} ; \mathrm{Y}=\mathrm{C} / \mathrm{T}, \mathrm{R}=\mathrm{A} / \mathrm{G}$ ) and reverse primer (R-1), 5'-ACTGCTGCCTCCCGTAGGAGT-3' (corresponding to nucleotides $345-365$ of Bacillus subtilis $16 \mathrm{~S}$ rDNA). HV region DNA was amplified according to Sadaie et al. (1997) and sequenced by using a BigDye Terminator Cycle Sequencing kit (Applied Biosystems). An ABI Prism model 3100 genetic analyser (Applied Biosystems) was used for electrophoresis and data collection. Sequence analysis was performed by using GeneWorks (version 2.0; IntelliGenetics) and GenBank/EMBL/DDBJ. Multiple sequence alignment was performed with CLUSTAL $\mathrm{W}$ version 1.7 (Thompson et al., 1994). Phylogenetic trees were constructed from evolutionary data, which were calculated with Kimura's two-parameter model (Kimura, 1980), by using the neighbour-joining method of Saitou \& Nei (1987). Robustness of individual branches was estimated by bootstrapping with 1000 replicates (Felsenstein, 1985).

To ascertain the conservation of the HV region within Brevibacillus brevis and its variation among different Brevibacillus species, we sequenced the HV regions of 29 strains that were identified previously as Brevibacillus brevis, as well as Aneurinibacillus migulanus DSM 8373, A. thermoaerophilus DSM 10155, Brevibacillus agri DSM 6366, Brevibacillus borstelensis DSM 6453, three strains of Brevibacillus sp. (DSM 4410, DSM 4411 and DSM 4412) and all type strains of Aneurinibacillus and Brevibacillus species. The results are summarized in Fig. 1 as a phylogenetic dendrogram, based on a comparison of 239 common nucleotide positions. Of the 29 Brevibacillus brevis strains, 13 clustered with Aneurinibacillus species, eight clustered with Bacillus species and eight clustered with Brevibacillus species. Of the eight that clustered with Brevibacillus species, two clustered with the type strain (DSM $30^{\mathrm{T}}$ ), along with Brevibacillus choshinensis DSM $8552^{\mathrm{T}}$ and Brevibacillus formosus DSM $9885^{\mathrm{T}}$, all showing $100 \%$ sequence similarity. 


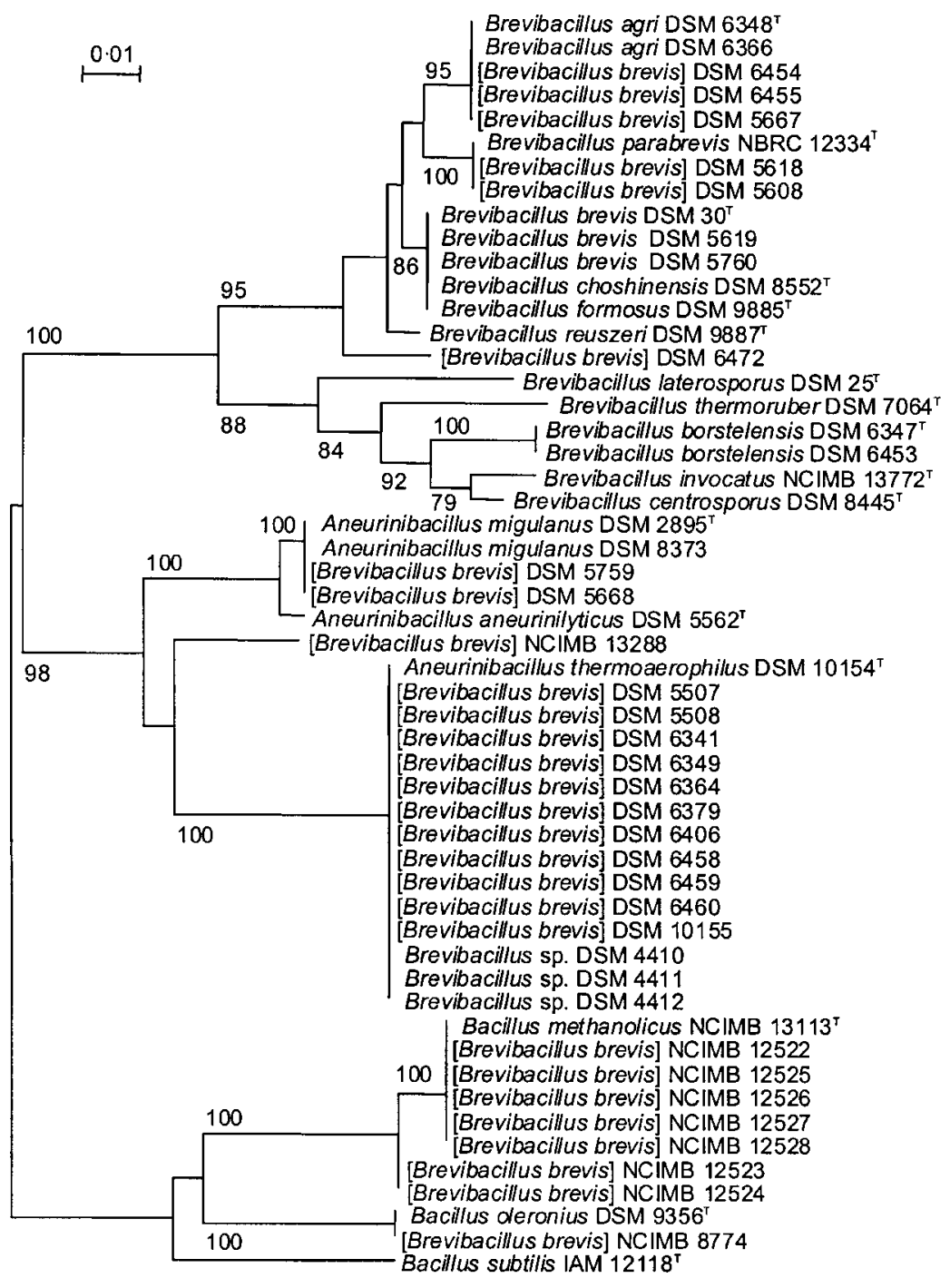

Fig. 1. Phylogenetic dendrogram based on the neighbour-joining method and derived from an alignment of $16 \mathrm{~S}$ rDNA HV region sequences from Brevibacillus brevis strains and related taxa. The final dataset included 239 unambiguously aligned sites. Numbers represent percentages of 1000 replicate bootstrap samplings (frequencies $<70 \%$ are not shown).

DSM 6472 and NCIMB 13288 did not cluster with any species of the genera Aneurinibacillus or Brevibacillus. Sequence similarity values within the clusters that contained A. migulanus, A. thermoaerophilus, Bacillus oleronius, Brevibacillus agri and Brevibacillus parabrevis were $100 \%$. In the Bacillus methanolicus cluster, NCIMB 12522, NCIMB 12525, NCIMB 12526, NCIMB 12527 and NCIMB 12528 all showed $100 \%$ sequence similarity to Bacillus methanolicus NCIMB $13113^{\mathrm{T}}$. However, NCIMB 12523 and NCIMB 12524 differed at five nucleotide positions, including two polymorphic positions, with the closest relative being Bacillus methanolicus NCIMB $13113^{\mathrm{T}}$. NCIMB 12523 differed from NCIMB 12524 at the two polymorphic sites. On the other hand, A. migulanus DSM 8373, A. thermoaerophilus DSM 10155, Brevibacillus agri DSM 6366 and Brevibacillus borstelensis DSM 6453 clustered with their individual type strains with $100 \%$ sequence similarity. Three strains of Brevibacillus sp. (DSM 4410, DSM 4411 and DSM 4412) also clustered with A. thermoaerophilus DSM $10154^{\mathrm{T}}$, with $100 \%$ sequence similarity.
Nearly-complete 16S rDNA sequences (1486-1526 bp long) were determined for [Brevibacillus brevis] strains DSM 5619, DSM 5760, DSM 6472, NCIMB 12523, NCIMB 12524 and NCIMB 13288, which showed ambiguous relationships in the $\mathrm{HV}$ region dendrogram, and for the type strains of Bacillus methanolicus, Aneurinibacillus and Brevibacillus species. The sequences of NCIMB 12523 (GenBank accession no. AB112728) and NCIMB 12524 (AB112729) were $99 \cdot 9 \%$ similar. NCIMB 12523 and NCIMB 12524 both showed a close relationship to Bacillus methanolicus NCIMB $13113^{\mathrm{T}}$ (AB112727), with $99 \cdot 2$ and $99 \cdot 3 \%$ similarity, respectively. Table 1 shows informative nucleotide positions among strains of the Brevibacillus brevisBrevibacillus choshinensis-Brevibacillus formosus cluster. When polymorphic nucleotide positions were removed, the 16S rDNA sequences of Brevibacillus brevis DSM $30^{\mathrm{T}}$, [Brevibacillus brevis] DSM 5619 and Brevibacillus formosus DSM $9885^{\mathrm{T}}$ were identical, but that of [Brevibacillus brevis] DSM 5760 differed from these three strains at nucleotide positions 612 and 620. By direct sequence comparison, 
Table 1. Differential nucleotide positions among strains of the Brevibacillus brevis-Brevibacillus formosus-Brevibacillus choshinensis cluster

Nucleotide positions are given by reference to the $16 \mathrm{~S}$ rDNA sequence of Bacillus subtilis (rrE). K, G/T; R, A/G; S, C/G; Y, C/T.

\begin{tabular}{|c|c|c|c|c|c|c|c|c|c|c|c|c|c|c|}
\hline \multirow[t]{2}{*}{ Strain } & \multicolumn{14}{|c|}{ Nucleotide position } \\
\hline & 72 & 73 & 74 & 81 & 82 & 83 & 187 & 200 & 388 & 612 & 620 & 1055 & 1057 & 1266 \\
\hline \multicolumn{15}{|l|}{ Brevibacillus brevis: } \\
\hline DSM $30^{\mathrm{T}}(\mathrm{AB} 101593)$ & K & S & $\mathrm{T}$ & A & $\mathrm{S}$ & $\mathrm{S}$ & $\mathrm{C}$ & $\mathrm{R}$ & $\mathrm{T}$ & G & $\mathrm{C}$ & $\mathrm{C}$ & $\mathrm{T}$ & A \\
\hline DSM 5619 (AB112730) & K & $S$ & $\mathrm{~T}$ & A & S & S & $\mathrm{Y}$ & G & $\mathrm{T}$ & G & $\mathrm{C}$ & $\mathrm{C}$ & $\mathrm{T}$ & A \\
\hline DSM 5760 (AB112731) & G & G & $\mathrm{T}$ & A & $\mathrm{C}$ & $\mathrm{C}$ & $\mathrm{C}$ & G & $\mathrm{T}$ & A & $\mathrm{T}$ & $\mathrm{C}$ & $\mathrm{T}$ & $\mathrm{R}$ \\
\hline Brevibacillus formosus DSM $9885^{\mathrm{T}}$ (AB112712) & $\mathrm{T}$ & $\mathrm{C}$ & $\mathrm{T}$ & A & G & G & Y & G & $\mathrm{T}$ & G & $\mathrm{C}$ & $\mathrm{C}$ & $\mathrm{T}$ & A \\
\hline Brevibacillus choshinensis DSM $8552^{\mathrm{T}}$ (AB112713) & $\mathrm{T}$ & $\mathrm{C}$ & $\mathrm{Y}$ & $\mathrm{R}$ & G & G & $\mathrm{C}$ & G & $\mathrm{C}$ & A & $\mathrm{T}$ & $\mathrm{T}$ & $\mathrm{C}$ & G \\
\hline
\end{tabular}

Brevibacillus choshinensis DSM $8552^{\mathrm{T}}$ differed from these four strains at six or seven reliable nucleotide positions (99.5-99.6\% similarity). Thus, Brevibacillus choshinensis DSM $8552^{\mathrm{T}}$ was an outlier of this cluster. However, nine informative nucleotide positions were removed as an alignment gap, making it difficult to describe the phylogeny of these five strains. Fig. 2 shows the phylogenetic tree of type strains of Aneurinibacillus and Brevibacillus species, [Brevibacillus brevis] DSM 6472 and [Brevibacillus brevis] NCIMB 13288, based on a comparison of 1430 common nucleotide positions. DSM 6472 and NCIMB 13288 were members of the genera Brevibacillus and Aneurinibacillus, respectively (these clusters were supported by high bootstrap values of $100 \%$ ) but they differed clearly from species with validly published names. $16 \mathrm{~S}$ rDNA sequence similarity of DSM 6472 to the type strains of Brevibacillus species ranged between $95 \cdot 4$ and $98 \cdot 8 \%$ and sequence similarity of NCIMB 13288 to type strains of Aneurinibacillus species ranged between $96 \cdot 8$ and $97 \cdot 9 \%$. These results indicate that DSM 6472 and NCIMB 13288 are novel species of the genera Brevibacillus and Aneurinibacillus, respectively.

DNA G + C contents of the 52 strains were determined by HPLC and each cluster, grouped by HV region sequence, is summarized in Table 2. The DNA G+C contents of strains in the Aneurinibacillus cluster ranged from 42.9 to $46 \cdot 7 \mathrm{~mol} \%$. The highest value, for [Brevibacillus brevis]
NCIMB 13288 , was $46 \cdot 7$ mol\%. DNA G + C contents of strains in the Bacillus methanolicus cluster ranged from $38 \cdot 4$ to $38.9 \mathrm{~mol} \%$, but these values were about $10 \mathrm{~mol} \%$ lower than values that were estimated by the renaturation rate method (De Ley et al., 1970; Arfman et al., 1992). The DNA $\mathrm{G}+\mathrm{C}$ content of Bacillus methanolicus NCIMB $13113^{\mathrm{T}}$, which was determined by the HPLC method at the TORAY Research Center (Tokyo, Japan), was 38.0 mol\% (our data, $38.6 \mathrm{~mol} \%$ ); thus, we considered that the discrepancy was due to differences in the methods being used. The DNA G + C content of [Brevibacillus brevis] NCIMB 8774 $(34.8 \mathrm{~mol} \%)$ was in good accordance with the value from Bacillus oleronius DSM 9356 ${ }^{\mathrm{T}}$. DNA G $+\mathrm{C}$ contents of strains in the Brevibacillus cluster ranged from $40 \cdot 4$ to $57 \cdot 3 \mathrm{~mol} \%$ and grouped well within each species cluster, respectively. The DNA G $+\mathrm{C}$ content of [Brevibacillus brevis] DSM 6472 was in the middle of the range, at $51.9 \mathrm{~mol} \%$.

Results of DNA-DNA hybridization experiments are shown in Table 2. In the clusters of A. migulanus, A. thermoaerophilus, Bacillus oleronius, Brevibacillus agri, Brevibacillus borstelensis and Brevibacillus parabrevis, there was at least $83 \%$ DNA-DNA relatedness between the type strain and other strains; thus, strains belonged to a single species within each cluster.

In the Bacillus methanolicus cluster, six strains with identical

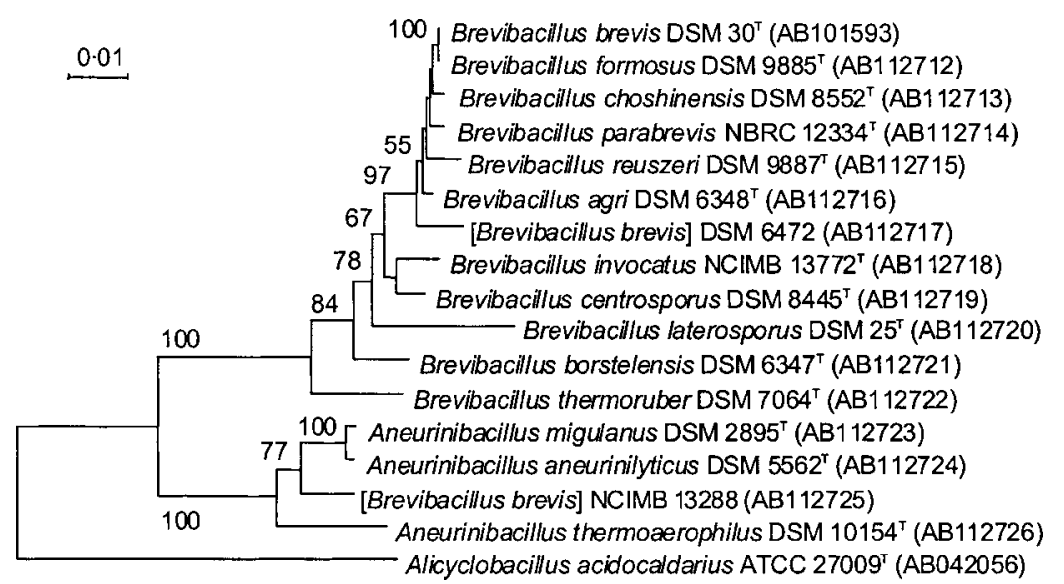

Fig. 2. Phylogenetic tree (constructed by using the neighbour-joining method) showing the phylogenetic position of strains DSM 6472 and NCIMB 13288 in relation to phylogenetically related Aneurinibacillus and Brevibacillus species, based on 16S rDNA sequences. Alicyclobacillus acidocaldarius ATCC $27009^{\top}$ served as an outgroup. The final dataset included 1430 unambiguously aligned sites. Numbers represent percentages of 1000 replicate bootstrap samplings (frequencies $<50 \%$ are not shown). 


\begin{tabular}{|c|c|c|c|c|c|c|c|c|c|c|c|c|c|c|c|c|c|c|c|c|c|c|c|}
\hline $\begin{array}{l}\text { Values are means of three or more repeate } \\
\text { Strain }\end{array}$ & $\begin{array}{l}\text { experiments. } \\
\text { DNA G+C }\end{array}$ & & & & & & & & & NA-I & DNA & lybric & izatic & n $(\%$ & wit & & & & & & & & \\
\hline Strain & $\begin{array}{c}\text { DNA G +C } \\
\text { content }(\mathrm{mol} \%)\end{array}$ & 1 & 2 & 3 & 4 & 5 & 6 & 7 & 8 & 9 & 10 & 11 & 12 & 13 & 14 & 15 & 16 & 17 & 18 & 19 & 20 & 21 & 22 \\
\hline 1. A. thermoaerophilus DSM $1054^{\mathrm{T}}$ & $44 \cdot 4$ & 100 & 13 & 12 & 9 & & & & & & 6 & & & & & & & & & & & & \\
\hline DSM 10155 & $44 \cdot 6$ & 92 & 11 & 11 & 10 & & & & & & 5 & & & & & & & & & & & & \\
\hline DSM 5507 & $45 \cdot 1$ & 95 & 14 & 11 & 10 & & & & & & 5 & & & & & & & & & & & & \\
\hline DSM 5508 & $44 \cdot 9$ & 100 & 14 & 11 & 10 & & & & & & 5 & & & & & & & & & & & & \\
\hline DSM 6341 & $44 \cdot 6$ & 100 & 13 & 11 & 11 & & & & & & 6 & & & & & & & & & & & & \\
\hline DSM 6349 & $44 \cdot 7$ & 100 & 14 & 11 & 11 & & & & & & 5 & & & & & & & & & & & & \\
\hline DSM 6364 & $44 \cdot 6$ & 97 & 10 & 13 & 9 & & & & & & 4 & & & & & & & & & & & & \\
\hline DSM 6379 & $44 \cdot 8$ & 96 & 11 & 10 & 10 & & & & & & 6 & & & & & & & & & & & & \\
\hline DSM 6406 & $45 \cdot 1$ & 94 & 12 & 12 & 10 & & & & & & 5 & & & & & & & & & & & & \\
\hline DSM 6458 & $44 \cdot 3$ & 99 & 12 & 10 & 12 & & & & & & 5 & & & & & & & & & & & & \\
\hline DSM 6459 & $44 \cdot 6$ & 100 & 12 & 9 & 8 & & & & & & 6 & & & & & & & & & & & & \\
\hline DSM 6460 & $45 \cdot 6$ & 90 & 11 & 8 & 10 & & & & & & 4 & & & & & & & & & & & & \\
\hline DSM 4410 & $44 \cdot 5$ & 92 & 12 & 8 & 10 & & & & & & 5 & & & & & & & & & & & & \\
\hline DSM 4411 & $45 \cdot 0$ & 94 & 13 & 10 & 10 & & & & & & 4 & & & & & & & & & & & & \\
\hline DSM 4412 & $44 \cdot 8$ & 96 & 14 & 9 & 12 & & & & & & 4 & & & & & & & & & & & & \\
\hline 2. A. thermoaerophilus NCIMB 13288 & $46 \cdot 7$ & 13 & 100 & 12 & 13 & & & & & & 4 & & & & & & & & & & & & \\
\hline 3. A. migulans DSM $2895^{\mathrm{T}}$ & $42 \cdot 9$ & 11 & 10 & 100 & 33 & & & & & & 5 & & & & & & & & & & & & \\
\hline DSM 8373 & $43 \cdot 0$ & 12 & 12 & 90 & 35 & & & & & & 6 & & & & & & & & & & & & \\
\hline DSM 5668 & $43 \cdot 0$ & 10 & 11 & 93 & 38 & & & & & & 6 & & & & & & & & & & & & \\
\hline DSM 5759 & $43 \cdot 0$ & 10 & 10 & 90 & 37 & & & & & & 5 & & & & & & & & & & & & \\
\hline 4. A. aneurinilyticus DSM $5562^{\mathrm{T}}$ & $43 \cdot 3$ & 10 & 11 & 35 & 100 & & & & & & 5 & & & & & & & & & & & & \\
\hline 5. Bacillus methanolicus ATCC $51375^{\mathrm{T}}$ & $38 \cdot 6$ & & & & & 100 & 59 & 59 & & & 4 & & & & & & & & & & & & \\
\hline NCIMB 12528 & $38 \cdot 6$ & & & & & 95 & 53 & 57 & & & 54 & & & & & & & & & & & & \\
\hline NCIMB 12527 & $38 \cdot 6$ & & & & & 95 & 56 & 58 & & & & & & & & & & & & & & & \\
\hline NCIMB 12526 & $38 \cdot 5$ & & & & & 96 & 54 & 52 & & & 5 & & & & & & & & & & & & \\
\hline NCIMB 12525 & $38 \cdot 5$ & & & & & 97 & 56 & 53 & & & 5 & & & & & & & & & & & & \\
\hline NCIMB 12522 & $38 \cdot 4$ & & & & & 96 & 62 & 56 & & & 5 & & & & & & & & & & & & \\
\hline 6. NCIMB 12523 & $38 \cdot 7$ & & & & & 60 & 100 & 58 & & & 5 & & & & & & & & & & & & \\
\hline 7. NCIMB 12524 & $38 \cdot 9$ & & & & & 63 & 58 & 100 & & & 5 & & & & & & & & & & & & \\
\hline 8. Bacillus oleronius DSM $9356^{\mathrm{T}}$ & $34 \cdot 9$ & & & & & 8 & 10 & 8 & 100 & & 5 & & & & & & & & & & & & \\
\hline NCIMB 8774 & $34 \cdot 8$ & & & & & & & & 89 & & 6 & & & & & & & & & & & & \\
\hline 9. Brevibacillus formosus DSM $9885^{\mathrm{T}}$ & $47 \cdot 0$ & & & & & & & & & 100 & 46 & 56 & 50 & 13 & 11 & 8 & 9 & 9 & 10 & 9 & 11 & 11 & 9 \\
\hline 10. Brevibacillus brevis DSM $30^{\mathrm{T}}$ & $47 \cdot 3$ & 6 & 5 & 6 & 4 & 5 & 6 & 6 & 4 & 53 & 100 & 55 & 55 & 14 & 13 & 11 & 11 & 12 & 10 & 11 & 12 & 10 & 9 \\
\hline 11. DSM 5619 & $47 \cdot 2$ & & & & & & & & & 60 & 58 & 100 & 58 & 14 & 13 & 9 & 10 & 9 & 9 & 10 & 13 & 10 & 10 \\
\hline 12. DSM 5760 & $47 \cdot 3$ & & & & & & & & & 61 & 51 & 58 & 100 & 13 & 14 & 10 & 12 & 12 & 11 & 9 & 12 & 10 & 9 \\
\hline 13. Brevibacillus chosinensis DSM $8552^{\mathrm{T}}$ & $48 \cdot 1$ & & & & & & & & & 19 & 14 & 10 & 14 & 100 & 12 & 10 & 10 & 12 & 9 & 10 & 13 & 9 & 10 \\
\hline 14. Brevibacillus parabrevis NBRC $12334^{\mathrm{T}}$ & $51 \cdot 8$ & & & & & & & & & 14 & 8 & 13 & 14 & 10 & 100 & 13 & 28 & 12 & 10 & 10 & 10 & 10 & 12 \\
\hline
\end{tabular}




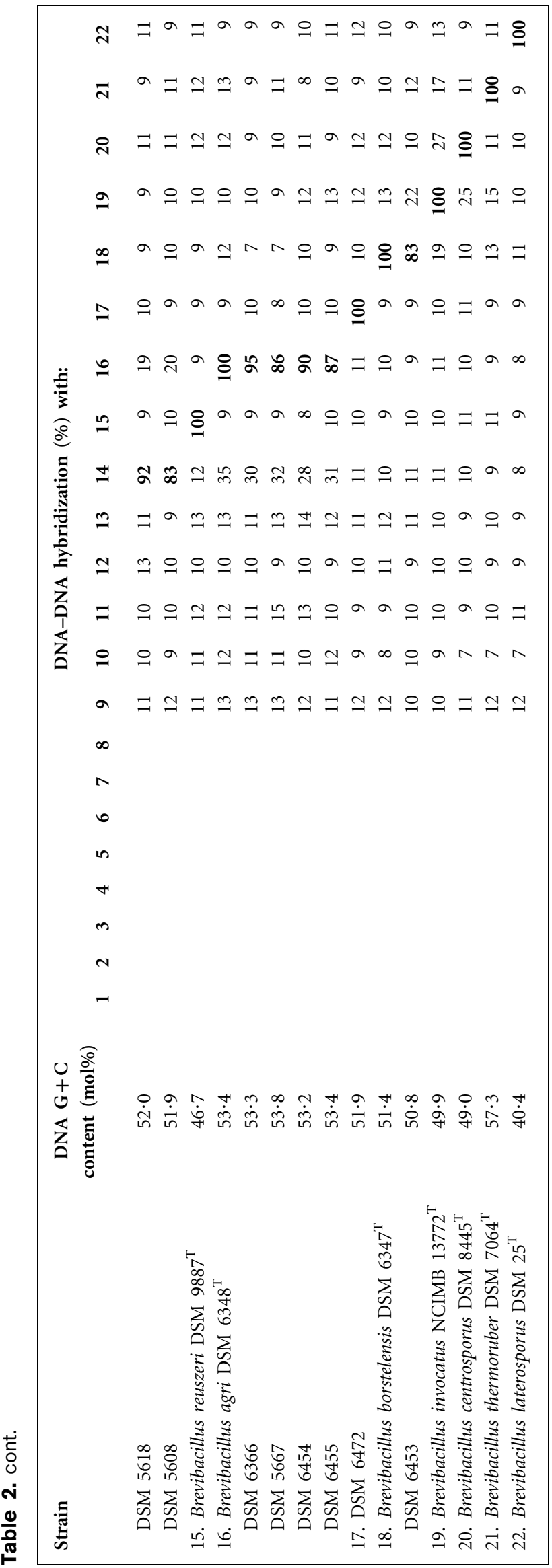

$\mathrm{HV}$ region sequences showed $>95 \%$ DNA-DNA relatedness to the type strain of Bacillus methanolicus and were thus considered to belong to this species. On the other hand, strains NCIMB 12523 and NCIMB 12524 showed intermediate DNA-DNA relatedness values (52-63\%) to other strains in the cluster, indicating some internal heterogeneity within Bacillus methanolicus (Arfman et al., 1992). Although strains NCIMB 12523 and NCIMB 12524 could be subspecies of Bacillus methanolicus, we regarded strains NCIMB 12522-NCIMB 12528 as provisional members of Bacillus methanolicus, in agreement with Arfman et al. (1992).

Brevibacillus brevis DSM 30 ${ }^{\mathrm{T}}$, DSM 5619, DSM 5760 and Brevibacillus formosus DSM $9885^{\mathrm{T}}$ showed intermediate DNA-DNA relatedness (46-61\%). A previous study (Shida et al., 1995) reported that DNA-DNA relatedness between the type strains of Brevibacillus brevis and Brevibacillus formosus was $6 \%$. In our study, DNA-DNA relatedness values were intermediate (46-61\%), which is consistent with their highly similar $16 \mathrm{~S}$ rDNA sequences (Amann et al., 1992; Hiraishi \& Ueda, 1994; Stackebrandt \& Goebel, 1994) and almost-identical DNA G $+C$ contents $(47 \cdot 0$ $47 \cdot 3 \mathrm{~mol} \%$ ). Thus, Brevibacillus brevis and Brevibacillus formosus are closely related genetically and, furthermore, there are strains that are intermediate between the species. These observations are also supported by a previous polyphasic taxonomic study (Logan et al., 2002). Although we tentatively regarded DSM 5619 and DSM 5760 as members of Brevibacillus brevis, further taxonomic studies are necessary to certify Brevibacillus brevis and Brevibacillus formosus as independent species. On the other hand, Brevibacillus choshinensis DSM $8552^{\mathrm{T}}$, an outlier of the cluster based on $16 \mathrm{~S}$ rDNA sequence analysis, had an HV region sequence that was almost identical to those of these strains (Table 1) and showed low DNA-DNA relatedness $(10-19 \%)$ to the other strains in the cluster. In API and other phenotypic analyses, Brevibacillus choshinensis could be distinguished from strains of Brevibacillus brevis and Brevibacillus formosus, whereas strains of Brevibacillus brevis and Brevibacillus formosus were indistinguishable (Logan et al., 2002); thus, Brevibacillus choshinensis could be regarded as an independent species.

NCIMB 13288 had 8-38\% DNA-DNA relatedness to strains within the Aneurinibacillus cluster. On the other hand, DSM 6472 had 8-12\% DNA-DNA relatedness to strains within the Brevibacillus cluster. DNA-DNA hybridization data and $16 \mathrm{~S}$ rDNA sequence analysis suggested that these strains were novel species of the genera Aneurinibacillus and Brevibacillus, respectively, and further taxonomic studies were carried out.

Differential phenotypic characteristics between DSM 6472 and closely related Brevibacillus reference strains, and between NCIMB 13288 and Aneurinibacillus type strains, are shown as Supplementary Tables A and B in IJSEM Online. Many biochemical characteristics of DSM 6472 were unreactive, but the strain could be distinguished from phylogenetically related species by a combination of 
characteristics. However, distinguishing between strains remained difficult as currently available phenotypic tests produced either no results or unreliable results from replicates (Logan et al., 2002).

NCIMB 13288 grew aerobically at 35 and $55^{\circ} \mathrm{C}$, but not at 30 or $60^{\circ} \mathrm{C}$; its optimal growth temperature was $45-50{ }^{\circ} \mathrm{C}$. This thermophilic property clearly distinguished NCIMB 13288 from the mesophilic species A. aneurinilyticus and A. migulanus. Whilst NCIMB 13288 and A. thermoaerophilus are both thermophilic species, several characteristics distinguish them from each other (see Supplementary Table A, available in IJSEM Online).

The major respiratory quinone of DSM 6472 and NCIMB 13288 was menaquinone 7 (MK-7). The fatty acid profiles of DSM 6472, NCIMB 13288 and type strains of Aneurinibacillus species were investigated (Table 3). In DSM 6472, major fatty acids were iso- $\mathrm{C}_{15: 0}(21 \cdot 29 \%)$, anteiso- $\mathrm{C}_{15: 0}$ $(41 \cdot 74 \%)$ and iso- $\mathrm{C}_{16: 0}(12 \cdot 40 \%)$. The profile of DSM 6472 was similar to those of other Brevibacillus species, but could be distinguished from them by a larger amount of iso- $\mathrm{C}_{16: 0}(12 \cdot 40 \%)$. In NCIMB 13288 , major fatty acids were iso- $\mathrm{C}_{15: 0}(57 \cdot 67 \%), \mathrm{C}_{16: 0}(6 \cdot 34 \%)$ and iso- $\mathrm{C}_{17: 0}$ (7.99\%); thus, this strain can be discriminated from other Aneurinibacillus species by lower amounts of anteiso- $\mathrm{C}_{15: 0}$, iso- $\mathrm{C}_{16: 0}$ and $\mathrm{C}_{16: 1} \omega 11 \mathrm{cis}$. Whilst fatty acid analysis may

Table 3. Fatty acid profiles of strains DSM 6472, NCIMB 13288 and reference strains

Taxa: 1, DSM 6472; 2, Range of Brevibacillus species; 3, NCIMB 13288; 4, A. thermoaerophilus DSM $10154^{\mathrm{T}}$; 5, A. migulanus DSM $2895^{\mathrm{T}} ; 6$, A. aneurinilyticus IAM $1077^{\mathrm{T}}$. Values are percentages of total fatty acids.

\begin{tabular}{|c|c|c|c|c|c|c|}
\hline Fatty acid & 1 & $2^{*}$ & 3 & 4 & 5 & 6 \\
\hline $\mathrm{C}_{14: 0}$ & & $0 \cdot 00-3 \cdot 07$ & $1 \cdot 86$ & & $3 \cdot 57$ & $1 \cdot 68$ \\
\hline iso- $\mathrm{C}_{14: 0}$ & $4 \cdot 51$ & $1 \cdot 72-12 \cdot 45$ & $1 \cdot 19$ & $5 \cdot 71$ & $4 \cdot 65$ & $1 \cdot 16$ \\
\hline iso- $\mathrm{C}_{14: 1} \omega 9$ cis & & & $3 \cdot 75$ & & & \\
\hline $\mathrm{C}_{15: 0}$ & $2 \cdot 32$ & $0 \cdot 00-1 \cdot 12$ & $1 \cdot 45$ & $1 \cdot 97$ & $1 \cdot 04$ & \\
\hline iso- $\mathrm{C}_{15: 0}$ & $21 \cdot 29$ & $15 \cdot 80-43 \cdot 91$ & $57 \cdot 67$ & $47 \cdot 64$ & $43 \cdot 87$ & $54 \cdot 17$ \\
\hline anteiso- $\mathrm{C}_{15: 0}$ & $41 \cdot 74$ & $20 \cdot 55-59 \cdot 80$ & $0 \cdot 90$ & $3 \cdot 34$ & $7 \cdot 32$ & $4 \cdot 35$ \\
\hline iso- $\mathrm{C}_{15: 1} \mathrm{~F}$ & & & $2 \cdot 08$ & & $1 \cdot 04$ & \\
\hline $\mathrm{C}_{16: 0}$ & $1 \cdot 59$ & $0 \cdot 22-7 \cdot 10$ & $6 \cdot 34$ & $3 \cdot 03$ & $7 \cdot 22$ & $6 \cdot 79$ \\
\hline iso- $\mathrm{C}_{16: 0}$ & $12 \cdot 4$ & $1 \cdot 50-6 \cdot 51$ & $3 \cdot 55$ & $19 \cdot 64$ & $3 \cdot 87$ & $1 \cdot 68$ \\
\hline iso- $\mathrm{C}_{16: 1} \mathrm{H}$ & & & & $1 \cdot 94$ & & \\
\hline $\mathrm{C}_{16: 1} \omega 5$ cis & & & $1 \cdot 11$ & & $1 \cdot 31$ & \\
\hline $\mathrm{C}_{16: 1} \omega 7$ cis alcohol & $3 \cdot 7$ & $0 \cdot 00-5 \cdot 49$ & & & & \\
\hline $\mathrm{C}_{16: 1} \omega 11$ cis & $1 \cdot 14$ & $0 \cdot 00-2 \cdot 78$ & & & $7 \cdot 59$ & $10 \cdot 92$ \\
\hline iso- $\mathrm{C}_{17: 0}$ & $2 \cdot 89$ & $0 \cdot 00-8 \cdot 09$ & $7 \cdot 99$ & $7 \cdot 26$ & $2 \cdot 17$ & $4 \cdot 67$ \\
\hline anteiso- $\mathrm{C}_{17: 0}$ & $5 \cdot 36$ & $0 \cdot 28-3 \cdot 38$ & & $1 \cdot 18$ & & \\
\hline iso- $\mathrm{C}_{17: 1} \omega 10$ cis & $1 \cdot 34$ & $0 \cdot 00-5 \cdot 42$ & & & $1 \cdot 8$ & $5 \cdot 04$ \\
\hline Summed feature 3 & & & $1 \cdot 64$ & & $4 \cdot 74$ & $1 \cdot 79$ \\
\hline Summed feature 4 & $1 \cdot 17$ & $0 \cdot 00-6 \cdot 18$ & $7 \cdot 38$ & $4 \cdot 14$ & $2 \cdot 73$ & $2 \cdot 38$ \\
\hline
\end{tabular}

${ }^{\star}$ Data from Logan et al. (2002). play a part in a polyphasic approach, we considered that it was not reliable on its own for identification of most taxa in the Bacillus group sensu lato, including Aneurinibacillus and Brevibacillus, as some other researchers have also suggested (Kämpfer, 1994; Logan et al., 2002).

In this study, many strains that were identified previously as Brevibacillus brevis were reidentified as A. migulanus, A. thermoaerophilus, Bacillus methanolicus, Bacillus oleronius, Brevibacillus agri and Brevibacillus parabrevis, based on both HV region sequence analyses and DNA-DNA hybridization experiments. Misnaming in the past may have been due to difficulty in identifying unreactive sporeformers and the fact that there are few useful distinctive phenotypic characteristics among Brevibacillus species (Logan et al., 2002). Whilst some strains show extremely close relationships between or within species, large-scale taxonomic studies that use many isolates and authentic strains are needed. Moreover, polyphasic taxonomic analyses clearly demonstrate that strains NCIMB 13288 and DSM 6472 are novel species of the genera Aneurinibacillus and Brevibacillus, respectively; therefore, the names Aneurinibacillus danicus sp. nov. and Brevibacillus limnophilus sp. nov. are proposed. The revived name Brevibacillus limnophilus is used for strain DSM $6472^{\mathrm{T}}$, which was originally deposited in the ARS Culture Collection as 'Bacillus limnophilus' by Porter in 1940 and was later identified as Bacillus brevis.

In members of the genera Aneurinibacillus and Brevibacillus, the HV region sequence is conserved within species and has diverged between species, enabling identification and grouping, as we have already shown for Alicyclobacillus, Bacillus and Paenibacillus. Whilst there are still a few genera that have not yet been investigated, the HV region sequence is a powerful index for rapid and convenient identification and grouping of aerobic spore-formers. This method is of particular significance to the food industry and is gradually being used more widely. Consensual nucleotide sequences among species of the genera Aneurinibacillus and Brevibacillus are shown as a Supplementary Figure in IJSEM Online.

\section{Description of Aneurinibacillus danicus sp. nov.}

Aneurinibacillus danicus (da'ni.cus. N.L. adj. danicus Danish, pertaining to Denmark).

Gram-variable, strictly aerobic, motile, ellipsoidal sporeforming, straight rods $(4 \cdot 0-6 \cdot 0 \mu \mathrm{m}$ long and $0 \cdot 8-1 \cdot 0 \mu \mathrm{m}$ wide). Ellipsoidal spores are oval and subterminal with swollen sporangia. Colonies on nutrient agar are circular, entire, smooth, flat, translucent and white $(5-10 \mathrm{~mm}$ in diameter after $48 \mathrm{~h}$ ). Temperature range for growth is $35-55^{\circ} \mathrm{C}$; optimum growth temperature is $45-50{ }^{\circ} \mathrm{C}$. Optimum $\mathrm{pH}$ is $6 \cdot 5-7 \cdot 0$; growth does not occur at pH $5 \cdot 5$ or $8 \cdot 0$. NCIMB $13288^{\mathrm{T}}$ fails to grow in nutrient broth that contains $>5 \%(\mathrm{w} / \mathrm{v}) \mathrm{NaCl}$ and under anaerobic conditions. Positive for oxidase and catalase (weak), but negative for urease, utilization of citrate and nitrate 
reductase. Aesculin, casein, tyrosine (weak), gelatin and DNA are hydrolysed, but arbutin and starch are not. Acid is produced from glycerol, erythritol (weak), D-arabinose, L-arabinose (weak), D-xylose, L-xylose, ribose, adonitol, D-fructose, D-mannose, L-sorbose, dulcitol, sorbitol, xylitol, D-lyxose, D-tagatose and D-arabitol. Major fatty acids are iso- $\mathrm{C}_{15: 0}, \mathrm{C}_{16: 0}$ and iso- $\mathrm{C}_{17: 0 .}$. Main quinone is MK-7. DNA $\mathrm{G}+\mathrm{C}$ content is $46 \cdot 7 \mathrm{~mol} \%$.

The type strain is NCIMB $13288^{\mathrm{T}}\left(=\operatorname{IAM} 15048^{\mathrm{T}}\right)$.

\section{Description of Brevibacillus limnophilus sp. nov.}

Brevibacillus limnophilus (lim.no' phi.lus. Gr. n. limnos lake; L. adj. philus from Gr. adj. philos loving, friendly to; N.L. masc. adj. limnophilus lake-loving).

Gram-variable, strictly aerobic, motile, ellipsoidal sporeforming, straight rods $(2 \cdot 2-4 \cdot 0 \mu \mathrm{m}$ long and $0 \cdot 5-0 \cdot 6 \mu \mathrm{m}$ wide). Ellipsoidal spores are oval and subterminal with swollen sporangia. Colonies on nutrient agar are circular, entire, smooth, convex, translucent and whitish-beige (3-4 $\mathrm{mm}$ in diameter after $48 \mathrm{~h}$ ). Temperature range for growth is $20-45^{\circ} \mathrm{C}$; optimum growth temperature is 30 $35^{\circ} \mathrm{C}$. Optimum $\mathrm{pH}$ is $7 \cdot 0-7 \cdot 5$; growth does not occur at pH 6.0 or 8.5 . DSM $6472^{\mathrm{T}}$ fails to grow in nutrient broth that contains $>2 \%(\mathrm{w} / \mathrm{v}) \mathrm{NaCl}$ and under anaerobic conditions. Positive for catalase, but negative for oxidase and urease activities, utilization of citrate and nitrate reductase. Aesculin and DNA (weak) are hydrolysed, but arbutin, casein, gelatin, starch and tyrosine are not. Acid is produced from glycerol, L-arabinose, rhamnose, ribose and $D$-fructose. Major fatty acids are iso- $C_{15: 0}$, anteiso- $C_{15: 0}$ and iso- $\mathrm{C}_{16: 0}$. Main quinone is MK-7. DNA G+C content is $51.9 \mathrm{~mol} \%$.

The type strain is DSM $6472^{\mathrm{T}}$ ( = NRRL NRS- $887^{\mathrm{T}}$ ).

\section{Acknowledgements}

We thank Professor Hans G. Trüper (Universität Bonn) for his valuable advice on nomenclature and Masayuki Suzuki (Tokyo Food Techno Co. Ltd) for his excellent technical assistance.

\section{References}

Amann, R. I., Lin, C., Key, R., Montgomery, L. \& Stahl, D. A. (1992). Diversity among Fibrobacter isolates: towards a phylogenetic classification. Syst Appl Microbiol 15, 23-31.

Arfman, N., Dijkhuizen, L., Kirchhof, G. \& 8 other authors (1992). Bacillus methanolicus sp. nov., a new species of thermotolerant, methanol-utilizing, endospore-forming bacteria. Int J Syst Bacteriol 42, 439-445.

Bligh, E. G. \& Dyer, W. J. (1959). A rapid method of total lipid extraction and purification. Can J Biochem Physiol 37, 911-917.

De Ley, J., Cattoir, H. \& Reynaerts, A. (1970). The quantitative measurement of DNA hybridization from renaturation rates. Eur J Biochem 12, 133-142.
Ezaki, T., Hashimoto, Y. \& Yabuuchi, E. (1989). Fluorometric deoxyribonucleic acid-deoxyribonucleic acid hybridization in microdilution wells as an alternative to membrane filter hybridization in which radioisotopes are used to determine genetic relatedness among bacterial strains. Int J Syst Bacteriol 39, 224-229.

Felsenstein, J. (1985). Confidence limits on phylogenies: an approach using the bootstrap. Evolution 39, 783-791.

Gordon, R. E., Haynes, W. C. \& Pang, C. H. (1973). The genus Bacillus. In Agriculture Handbook (no. 427). Washington, DC: US Department of Agriculture.

Goto, K., Omura, T., Hara, Y. \& Sadaie, Y. (2000). Application of the partial $16 \mathrm{~S}$ rDNA sequence as an index for rapid identification of species in the genus Bacillus. J Gen Appl Microbiol 46, 1-8.

Goto, K., Tanimoto, Y., Tamura, T., Mochida, K., Arai, D., Asahara, M., Suzuki, M., Tanaka, H. \& Inagaki, K. (2002a). Identification of thermoacidophilic bacteria and a new Alicyclobacillus genomic species isolated from acidic environments in Japan. Extremophiles 6, 333-340.

Goto, K., Mochida, K., Asahara, M., Suzuki, M. \& Yokota, A. (2002b). Application of the hypervariable region of the $16 \mathrm{~S}$ rDNA sequence as an index for the rapid identification of species in the genus Alicyclobacillus. J Gen Appl Microbiol 48, 243-250.

Goto, K., Kato, Y., Asahara, M. \& Yokota, A. (2002c). Evaluation of the hypervariable region in the $16 \mathrm{~S}$ rDNA sequence as an index for rapid species identification in the genus Paenibacillus. J Gen Appl Microbiol 48, 281-285.

Heyndrickx, M., Lebbe, L., Vancanneyt, M. \& 7 other authors (1997). A polyphasic reassessment of the genus Aneurinibacillus, reclassification of Bacillus thermoaerophilus (Meier-Stauffer et al. 1996) as Aneurinibacillus thermoaerophilus comb. nov., and emended descriptions of A. aneurinilyticus corrig., A. migulanus, and A. thermoaerophilus. Int J Syst Bacteriol 47, 808-817.

Hiraishi, A. \& Ueda, Y. (1994). Intrageneric structure of the genus Rhodobacter: transfer of Rhodobacter sulfidophilus and related marine species to the genus Rhodovulum gen. nov. Int J Syst Bacteriol 44, 15-23.

Kämpfer, P. (1994). Limits and possibilities of total fatty acid analysis for classification and identification of Bacillus species. Syst Appl Microbiol 17, 86-98.

Kimura, M. (1980). A simple method for estimating evolutionary rates of base substitutions through comparative studies of nucleotide sequences. J Mol Evol 16, 111-120.

Logan, N. A., Forsyth, G., Lebbe, L. \& 8 other authors (2002). Polyphasic identification of Bacillus and Brevibacillus strains from clinical, dairy and industrial specimens and proposal of Brevibacillus invocatus sp. nov. Int J Syst Evol Microbiol 52, 953-966.

Meier-Stauffer, K., Busse, H.-J., Rainey, F. A. \& 7 other authors (1996). Description of Bacillus thermoaerophilus sp. nov., to include sugar beet isolates and Bacillus brevis ATCC 12990. Int J Syst Bacteriol 46, 532-541.

Metcalfe, L. D., Schmitz, A. A. \& Pelka, J. R. (1996). Rapid preparation of fatty acid esters from lipids for gas chromatographic analysis. Anal Chem 38, 514-515.

Migula, W. (1900). System der Bakterien, vol. 2. Jena: Gustav Fisher. Nakamura, L. K. (1991). Bacillus brevis Migula 1900 taxonomy: reassociation and base composition of DNA. Int J Syst Bacteriol 41, 510-515.

Nakamura, L. K. (1993). DNA relatedness of Bacillus brevis Migula 1900 strains and proposal of Bacillus agri sp. nov., nom. rev., and Bacillus centrosporus sp. nov., nom. rev. Int J Syst Bacteriol 43, 20-25.

Nakamura, L. K. \& Swezey, J. (1983a). Taxonomy of Bacillus circulans Jordan 1890: base composition and reassociation of deoxyribonucleic acid. Int J Syst Bacteriol 33, 46-52. 
Nakamura, L. K. \& Swezey, J. (1983b). Deoxyribonucleic acid relatedness of Bacillus circulans Jordan 1890 strains. Int J Syst Bacteriol 33, 703-708.

Sadaie, Y., Yata, K., Fujita, M., Sagai, H., Itaya, M., Kasahara, Y. \& Ogasawara, N. (1997). Nucleotide sequence and analysis of the phoB-rrnE-groESL region of the Bacillus subtilis chromosome. Microbiology 143, 1861-1866.

Saitou, N. \& Nei, M. (1987). The neighbor-joining method: a new method for reconstructing phylogenetic trees. Mol Biol Evol 4, 406-425.

Sano, H., Sakai, M. \& Nishijima, M. (1996). Application of MS to the search of the products from marine bacteria. J Mass Spectrom Soc Jpn 44, 377-391.

Shida, O., Takagi, H., Kadowaki, K., Yano, H., Abe, M., Udaka, S. \& Komagata, K. (1994a). Bacillus aneurinolyticus sp. nov., nom. rev. Int J Syst Bacteriol 44, 143-150.

Shida, O., Takagi, H., Kadowaki, K., Udaka, S. \& Komagata, K. (1994b). Bacillus galactophilus is a later subjective synonym of Bacillus agri. Int J Syst Bacteriol 44, 172-173.

Shida, O., Takagi, H., Kadowaki, K., Udaka, S., Nakamura, L. K. \& Komagata, K. (1995). Proposal of Bacillus reuszeri sp. nov., Bacillus formosus sp. nov., nom. rev., and Bacillus borstelensis sp. nov., nom. rev. Int J Syst Bacteriol 45, 93-100.
Shida, O., Takagi, H., Kadowaki, K. \& Komagata, K. (1996). Proposal for two new genera, Brevibacillus gen. nov. and Aneurinibacillus gen. nov. Int J Syst Bacteriol 46, 939-946.

Stackebrandt, E. \& Goebel, B. M. (1994). Taxonomic note: a place for DNA-DNA reassociation and $16 \mathrm{~S}$ rRNA sequence analysis in the present species definition in bacteriology. Int J Syst Bacteriol 44, 846-849.

Takagi, H., Shida, O., Kadowaki, K., Komagata, K. \& Udaka, S. (1993). Characterization of Bacillus brevis with descriptions of Bacillus migulanus sp. nov., Bacillus choshinensis sp. nov., Bacillus parabrevis sp. nov., and Bacillus galactophilus sp. nov. Int J Syst Bacteriol 43, 221-231.

Tamaoka, J. \& Komagata, K. (1984). Determination of DNA base composition by reverse-phase high-performance liquid chromatography. FEMS Microbiol Lett 25, 125-128.

Thompson, J. D., Higgins, D. G. \& Gibson, T. J. (1994). CLUSTAL W: improving the sensitivity of progressive multiple sequence alignment through sequence weighting, position-specific gap penalties and weight matrix choice. Nucleic Acids Res 22, 4673-4680.

Treisman, R. (1989). Purification of plasmid DNA. In Molecular Cloning: a Laboratory Manual, 2nd edn, pp. 40-41. Edited by J. Sambrook, E. F. Fritsch \& T. Maniatis. Cold Spring Harbor, NY: Cold Spring Harbor Laboratory. 